\title{
Growth of $\mathrm{Ge}$ nanoparticles on $\mathrm{SiO}_{2} / \mathrm{Si}$ interfaces during annealing of plasma enhanced chemical vapor deposited thin films
}

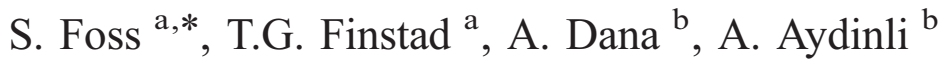 \\ a Department of Physics, University of Oslo, PO Box 1048-Blindern, N-0316, Norway \\ ${ }^{\mathrm{b}}$ Department of Physics, Bilkent University, 06800 Ankara, Turkey
}

Available online 16 January 2007

\begin{abstract}
Multilayer germanosilicate $\left(\mathrm{Ge}: \mathrm{SiO}_{2}\right)$ films have been grown by plasma enhanced chemical vapor deposition. Each Ge:SiO${ }_{2}$ layer is separated by a pure $\mathrm{SiO}_{2}$ layer. The samples were heat treated at $900{ }^{\circ} \mathrm{C}$ for 15 and $45 \mathrm{~min}$. Transmission electron microscopy investigations show precipitation of particles in the layers of highest Ge concentration. Furthermore there is evidence of diffusion between the layers. This paper

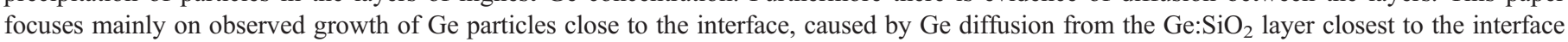
through a pure $\mathrm{SiO}_{2}$ layer and to the interface. The particles grow as spheres in a direction away from the interface. Particles observed after 15 min anneal time are $4 \mathrm{~nm}$ in size and are amorphous, while after $45 \mathrm{~min}$ anneal time they are $7 \mathrm{~nm}$ in size and have a crystalline diamond type Ge structure.
\end{abstract}

(C) 2006 Elsevier B.V. All rights reserved.

Keywords: Ge; Nanoparticle; Interfaces; Diffusion

\section{Introduction}

The underlying motivation of this work is control of nanometer sized Ge-particle growth. A desired structure is an insulator in which nanometer sized Ge particles are embedded. Embedded semiconductor nanoparticles can find applications in optoelectronic devices [1-3] or charge storage devices [4-8]. The physical properties and ultimately the usefulness of the nanoparticles depend on the particle size and the particles' location with respect to other parts (interfaces, luminescent atoms, other nanoparticles etc) of a device. Ge has a relatively large excitonic Bohr radius of about $25 \mathrm{~nm}$ (compared to $\sim 5 \mathrm{~nm}$ for Si). Thus quantum confinement effects can theoretically be observed over a relatively large and easy controllable range of nanocrystal sizes. The quantum confinement effects of most current interest are the size dependent energy levels and radiative transition probabilities. The energy levels of $\mathrm{Ge}$

\footnotetext{
* Corresponding author.

E-mail address: stefoss@fys.uio.no (S. Foss).
}

nanocrystals have recently been measured and modeled [9]. For memory applications of Ge nanocrystals the energy levels play an important role in the charging and discharging of nanocrystals and the control of the size and location of nanocrystals is a key element.

The formation of Ge nanocrystals in $\mathrm{SiO}_{2}$ has been reported by many authors using several different methods for the preparation of the nanocrystals such as ion implantation into $\mathrm{SiO}_{2}[3,10]$, co-sputtering of $\mathrm{Ge}$ and $\mathrm{SiO}_{2}[7,8]$, electron beam evaporation of $\mathrm{Ge}$ sandwiched between $\mathrm{SiO}_{2}$ [6], oxidation of $\mathrm{Si}-\mathrm{Ge}$ layers [11] or plasma enhanced chemical vapor deposition (PECVD) [12]. This paper presents a study of multilayer germanosilicate $\left(\mathrm{Ge}: \mathrm{SiO}_{2}\right)$ films made by plasma enhanced chemical vapor deposition. Each $\mathrm{Ge}: \mathrm{SiO}_{2}$ layer, with different Ge concentrations, is separated by a pure $\mathrm{SiO}_{2}$ layer. Such multilayers are used in order to test Ge-particle growth in several layers at a time after annealing. This provides an efficient and time saving approach to obtain data on nanoparticle growth. The present work focuses mainly on a phenomenon in which Ge atoms diffuse towards the interface between the film and the Si substrate and precipitation of $\mathrm{Ge}$ particles close to this interface. The diffusion in the films and 
the nanocrystal formation with respect to the interfaces could be different than those observed by other preparation methods for the films.

\section{Experimental}

The samples were prepared as six layers of germanosilacate (here notated as $\mathrm{Ge}: \mathrm{SiO}_{2}$ ), sandwiched between silicon oxide $\left(\mathrm{SiO}_{2}\right)$ layers, and grown onto a polished single crystal (100) Si wafer. The oxide films were deposited by a PECVD technique using a model PlasmaLab $8510 \mathrm{C}$ reactor. The PECVD process was carried out with the sample at $350{ }^{\circ} \mathrm{C}$ and process pressure of 1000 mTor under an applied RF power of $12 \mathrm{~W}$. The process uses $\mathrm{He}$ and $\mathrm{N}_{2}$ as carrier gases and precursor gases of $\mathrm{SiH}_{4}$, $\mathrm{NO}_{2}$ and $\mathrm{GeH}_{4}$. The flow rates were $200 \mathrm{sccm}$ of $\mathrm{SiH}_{4}(2 \%$ in $\mathrm{N}_{2}$ ), $180 \mathrm{sccm}$ of $\mathrm{NO}_{2}$ for the $\mathrm{SiO}_{2}$ layers and various flow rates of $\mathrm{GeH}_{4}(2 \%$ in $\mathrm{He})$. The as deposited structure of the sample is schematically shown in Fig. 1. The first layer grown on the $\mathrm{Si}$ wafer, layer 0, was a pure $\mathrm{SiO}_{2}$ layer followed by the $\mathrm{Ge}: \mathrm{SiO}_{2}$ layer of highest $\mathrm{Ge}$ concentration, layer 1 . Then follows pairs of layers of pure $\mathrm{SiO}_{2}$ and $\mathrm{Ge}: \mathrm{SiO}_{2}$ with decreasing $\mathrm{Ge}$ concentration, where only the Ge containing layers are numbered. As indicated in Fig. 1 the $\mathrm{GeH}_{4}$ flow rates were 120, 110,

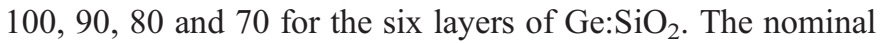
concentration of these layers was determined from the calibration samples measured by photoelectron spectroscopy. The nominal $\mathrm{Ge}$ atomic concentrations of the layers are thus $0.132,0.122,0.115,0.109,0.092$ and 0.08 as indicated in Fig. 1. The wafer was cut in pieces and samples annealed in a dry $\mathrm{N}_{2}$ atmosphere at various temperatures. Here we report on 700 and $900{ }^{\circ} \mathrm{C}$.

Transmission electron microscopy (TEM) specimens were made by gluing two substrates together with the film side facing each other. These samples were then cut and mechanically polished down to less than $50 \mu \mathrm{m}$ in thickness. The samples

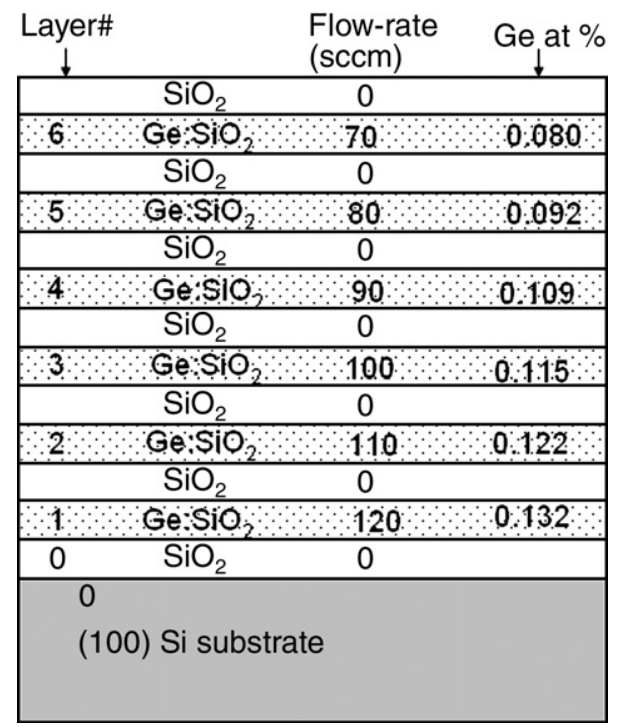

Fig. 1. Schematic drawing of the layered structure of the PECVD deposited films. The flow rates for $\mathrm{GeH}_{4}$ are given in sccm as well as the nominal atomic percentage in the layers.

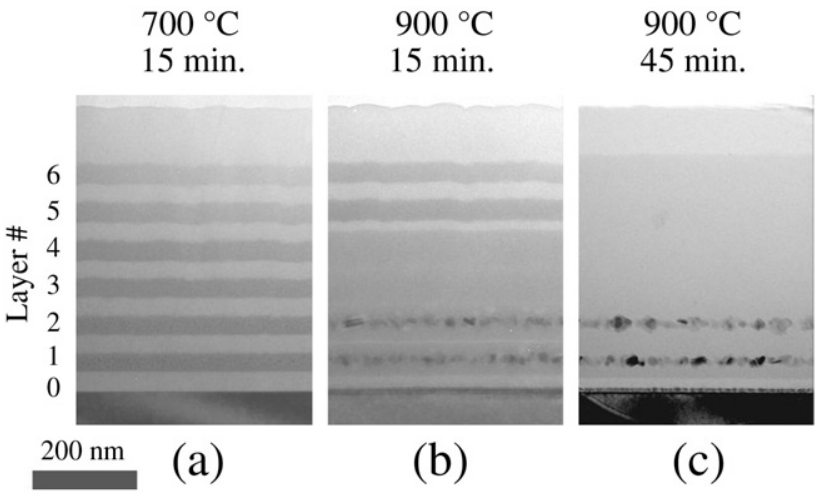

Fig. 2. TEM micrograph overview of the samples. Samples A, B and C have different annealings. Dark and light grey areas correspond to high and low content of Ge, respectively. Precipitations of particles are seen in layers 1 and 2 of samples B and C.

were subsequently ion milled until electron transparency using a $5 \mathrm{keV} \mathrm{Ar}^{+}$ion beam inclined at $5^{\circ}$ angle from one side and $7^{\circ}$ angle from the other side simultaneously. The TEM was a JEOL $2010 \mathrm{~F}$ operated at an acceleration voltage of $200 \mathrm{keV}$.

\section{Results and discussion}

Fig. 2 shows cross-section TEM overview images of the multilayered samples where sample $\mathrm{A}$ is annealed at $700^{\circ} \mathrm{C}$ for 15 , sample B is annealed at $900{ }^{\circ} \mathrm{C}$ for $15 \mathrm{~min}$ and sample $\mathrm{C}$ is annealed at $900{ }^{\circ} \mathrm{C}$ for $45 \mathrm{~min}$. The layer numbering is also indicated in the figure. The contrast is due to increased absorption and scattering properties of heavier elements. The dark grey areas thus correspond to areas with high Ge content.

From Fig. 2 an interesting evolution of the contrast between the layers can be noted. All the $\mathrm{Ge}: \mathrm{SiO}_{2}$ layers are clearly distinguished for sample A annealed at $700{ }^{\circ} \mathrm{C}$ for $15 \mathrm{~min}$. In the micrograph of sample $\mathrm{B}$, which is annealed at $900{ }^{\circ} \mathrm{C}$ for $15 \mathrm{~min}$, there is no contrast between layers 2 and 3 and also clearly much less contrast between layers 1 and 2 than there is in sample A. In the micrograph of sample $\mathrm{C}$, there is no contrast between any layers. The changes in the contrast between the different layers are attributed to $\mathrm{Ge}$ diffusion within the $\mathrm{SiO}_{2}$ film even if the concentration profiles of $\mathrm{Ge}$ cannot be measured directly from the darkness of the micrographs. From the contrast one can see that a thin layer of low Ge content exists between layers 1 and 2 in sample B. There is no such layer visible between layers 3 and 4 in the same sample B. Even without considering the difference in overall $\mathrm{Ge}$ concentration in layers 1 to 2 versus layers 3 to 4 , we can deduce that the Ge diffusion proceeds differently between these layer pairs. This difference in diffusion is further emphasized by considering the difference in overall $\mathrm{Ge}$ concentrations. The difference in diffusion behavior is attributed to the nucleation of Ge precipitates in layers 1 and 2, thus depleting the local $\mathrm{SiO}_{2}$ solution of Ge.

Ge particles form in layers 1-2 of sample B and C, as shown in Fig. 2, and selected area diffraction (SAD) reveals the presence of a crystalline Ge diamond type structure in these layers. This is as anticipated and the multilayer structures have been used for 
(a)

$$
900{ }^{\circ} \mathrm{C}
$$

(b)

15 minutes
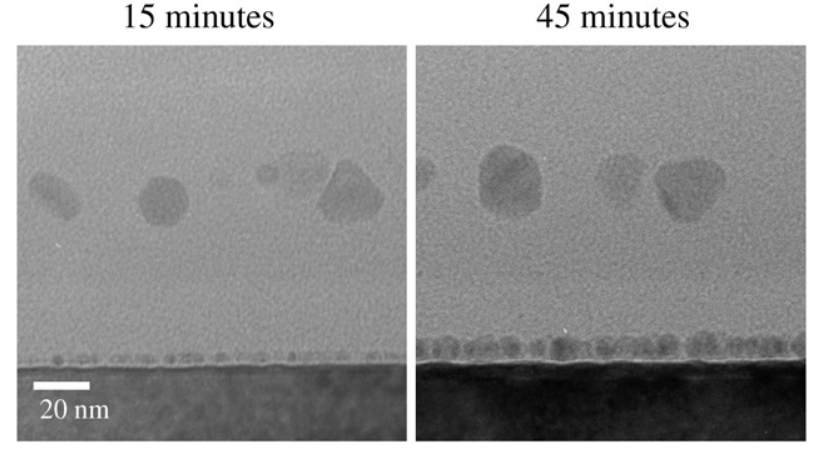

Fig. 3. Close up view of particles grown on the interface and Ge particles in layer 1 . The interface particles are round and grow in a direction away from the interface.

studying the size distribution in the layers as a function of a wider annealing parameter variation than presently reported.

Nanoparticles have also been observed to grow in the vicinity of the $\mathrm{Si} / \mathrm{SiO}_{2}$ interface in samples $\mathrm{B}$ and $\mathrm{C}$ (annealed at $900^{\circ} \mathrm{C}$ ) as seen in Fig. 3. The nanocrystals formed in layer 1 are large with some facets, while the particles formed near the interface appears more spherical. The latter particles have an average diameter of $4 \mathrm{~nm}$ after $15 \mathrm{~min}$ annealing time at $900{ }^{\circ} \mathrm{C}$ and are found to have an amorphous structure. Interface particles grown during $45 \mathrm{~min}$ annealing time at $900{ }^{\circ} \mathrm{C}$ have an average diameter of $7 \mathrm{~nm}$ and have a crystalline structure as can be seen from the lattice fringes in Fig. 4. The nanocrystals have a random orientation with respect to the Si substrate. Their crystal structure has been identified as that of diamond crystal structure from SAD patterns as seen in Fig. 5 and the high resolution electron microscopy images of Fig. 4.

There seems to be a very little contact between the Si substrate and the Ge particles. It is however difficult to determine with precision whether these particles are in contact with the interface, since there would be a question whether the particles and the substrate are separated by $\sim 1 \mathrm{~nm}$ of $\mathrm{SiO}_{2}$ or if there is a very small contact area. Contrast imaging is not a reliable tool in this case, because the contrast between the particles and the $\mathrm{SiO}_{2}$ is diffused near the particle edge. We have analyzed the high resolution electron microscopy (HREM) pattern of sample

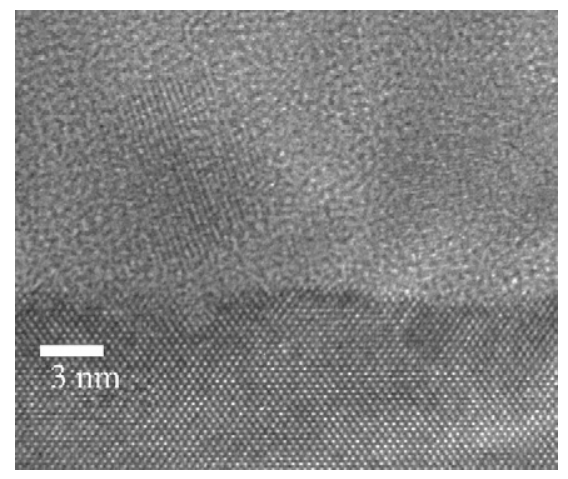

Fig. 4. HRTEM image of two interface particles. The lattice fringes correspond to (111) Ge and (220) Ge.

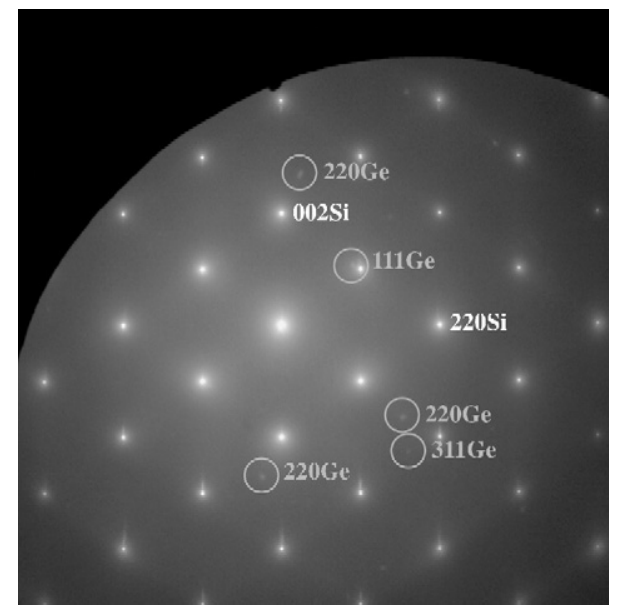

Fig. 5. SAD of the substrate and the interface particles. Ge reflections are identified with $1 \%$ accuracy and are marked by grey circles.

$\mathrm{C}$ and examined whether the HREM pattern of the Ge crystals extends onto the HREM pattern of the Si substrate and this analysis shows that $25 \%$ of the particles ( 8 out of 32 ) have contact with the interface, and 75\% (24 out of 32) do not. This analysis is not possible for sample $\mathrm{B}$, in which the particles are amorphous. An explanation as to why some particles are not observed to have direct contact with the interface is that the cross-section analyzed in the micrographs are thin slices of the samples and the specimen surface can cut off the nanocrystals at various arbitrary planes, thus the actual percentage of nanocrystrals that are not in contact with the silicon substrate may be smaller than $75 \%$.

Diffusion of Ge from layer 1 to the interface may be the source of the precipitated Ge close to the interface, referred to as the interface particles. A driving force for nucleation is an excess of $\mathrm{Ge}$ in the $\mathrm{SiO}_{2}$ matrix. The excess Ge concentration will not be the largest at the interface by a normal diffusion process and the particles' proximity to the interface indicates that the particles nucleate close to the surface because the interface (or something else in the vicinity of the interface) decreases the surface energy of the Ge nucleii. It may very well be that the particles nucleate onto the Si substrate itself, since

(a)

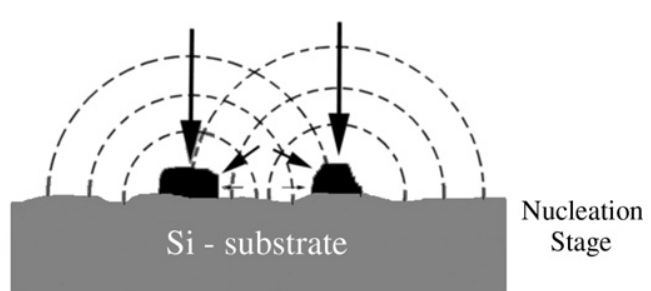

(b)

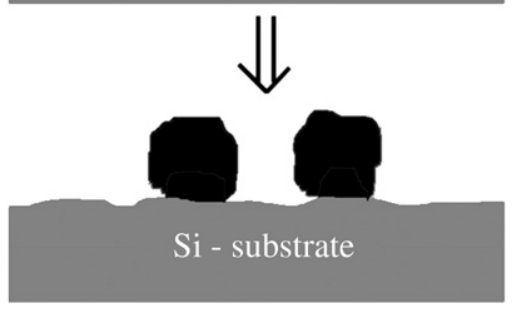

Grown

Particle
Fig. 6. Illustration of a possible interface particle growth process. 
the grain boundary energy would be less between $\mathrm{Si}$ and $\mathrm{Ge}$ than between $\mathrm{SiO}_{2}$ and $\mathrm{Ge}$. The accumulation of $\mathrm{Ge}$ at the $\mathrm{Si} /$ $\mathrm{SiO}_{2}$ interface has been reported before [10]. Avella et al. [11] and Choi et al. [7] have reported nucleation of Ge nanocrystals close to a substrate surface, from $\mathrm{a} \mathrm{SiO}_{2}$ film with uniform $\mathrm{Ge}$ concentration. Choi et al. [7] have argued that the formation of interface $\mathrm{Ge}$ particles could be influenced by $\mathrm{Si}$ diffusion through the $\mathrm{SiO}_{2}$ film [13] and the $\mathrm{Si}$ substrate being the source of the Si. Ge may then form by a reduction mechanism [14].

For nucleation onto the Si substrate, the expected shape of the particles is that of half-spheres rather than round particles. The half-sphere shape would be favored for the reduction of the grain boundary energy. What follows describes a possible explanation for the observed round shape in terms of the diffusion and precipitation process. Referring to Fig. 3, the particles seem to grow in a direction away from the interface. If extrapolating the data in Fig. 3, the particles may start at a point at the interface or close to it, and then grow as spheres (see Fig. 6), keeping the initial contact between the particles and the interface at a near constant level. The growth rate in the direction towards the interface would be negligible. The growth rate in the direction away from the interface is highest and twice the rate of the growth in the direction parallel to the interface. The reason for this may be that during growth or nucleation of Ge particles, there would be a depletion of the local Ge concentration in the region surrounding the particles. Between two Ge particles in close proximity, there would be an overlap of the depletion zones. Consequently, the Ge concentration should be lower in the region between the particles. Since the Ge growth and the precipitation rate depend on the Ge concentration in $\mathrm{SiO}_{2}$, the fastest growth direction is away from the interface. Between the particles the growth rate should be small, and even less closer to the substrate interface. It is also speculated whether a low mobility of Ge in a layer between the particles and the interface, for example a thin thermal $\mathrm{SiO}_{2}$ formed in the reactor during ramping up to the growth temperature for the deposition; a thermal oxide may be more dense than the deposited oxide and could limit Ge diffusion towards the interface and also the growth of the Ge particles into the substrate.

\section{Conclusion}

A multilayer $\mathrm{GeSiO}_{2}$ has been studied with a TEM. Precipitation of Ge nanocrystals has been observed in the layers of highest Ge. Evidence based on high contrast TEM images suggests a substantial degree of Ge diffusion in the sample. Precipitation of Ge particles close to an interface has been observed. The presence of Ge close to the interface is due to diffusion across a $40 \mathrm{~nm}$ layer. The nucleation process is unknown. The particles grow away from the interface as spheres. After $15 \mathrm{~min}$ annealing at $900{ }^{\circ} \mathrm{C}$ the particles are $4 \mathrm{~nm}$ amorphous particles. After $45 \min 900{ }^{\circ} \mathrm{C}$ annealing, the particles are $7 \mathrm{~nm}$ crystalline particles.

\section{Acknowledgement}

This work was partly supported by the European Commission through the project called SEMINANO under the contract NMP4-CT-2004-505285.

\section{References}

[1] G. Kartopu, V.A. Karavanskii, U. Serincan, R. Turan, R.E. Hummel, Y. Ekinci, A. Gunnaes, T.G. Finstad, Phys. Status Solidi, Appl. Mater. Sci. 202 (2005) 1472.

[2] C.L. Heng, T.G. Finstad, P. Storås, Y.J. Li, A. Gunnæs, O. Nilsen, Appl. Phys. Lett. 85 (2004) 4475.

[3] W. Skorupa, L. Rebohle, T. Gebel, Appl. Phys., A Mater Sci. Process. 76 (2003) 1049.

[4] S. Tiwari, F. Rana, H. Hanafi, A. Hartstein, E.F. Crabbe, K. Chan, Appl. Phys. Lett. 68 (1996) 1377.

[5] A. Dana, I. Akca, O. Ergun, A. Aydinli, R. Turan, J. Appl. Phys. (submitted for publication).

[6] C.L. Heng, T.G. Finstad, Physica E-Low-Dimens. Syst. Nanostruct. 26 (2005) 386.

[7] W.K. Choi, V. Ho, V. Ng, Y.W. Ho, S.P. Ng, W.K. Chim, Appl. Phys. Lett. 86 (2005) 143114.

[8] C.L. Heng, T.G. Finstad, Y.J. Li, A.E. Gunnæs, A. Olsen, P. Storås, Microelectron. J. 36 (2005) 531.

[9] Y. Nakamura, K. Watanabe, Y. Fukuzawa, M. Ichikawa, Appl. Phys. Lett. 87 (2005) 133119.

[10] E.S. Marstein, A.E. Gunnæs, U. Serincan, R. Turan, A. Olsen, T.G. Finstad, Surf. Coat. Technol. 158-159 (2002) 544.

[11] M. Avella, A.C. Prietoa, J. Jimemenez, A. Rodriguez, J. Sangrador, T. Rodrguez, Solid State Commun. 136 (2005) 224.

[12] S. Agan, A. Celik-Aktas, J.M. Zuo, A. Dana, A. Aydinli, Appl. Phys., A Mater. Sci. Process. 83 (2006) 107.

[13] Y. Maeda, Phys. Rev. B 51 (1995) 658.

[14] W.S. Liu, J.S. Chen, M.A. Nicolet, V. Arbet-Engels, K.L. Wang, J. Appl. Phys. 72 (1992) 4444. 